\title{
Preparation, Characterization and Optimization of Etoposide-Loaded Gold Nanoparticles Based on Chemical Reduction Method

\author{
Maha M. Ali ${ }^{*}, 1$, Nawal A. Rajab* and Alaa A. Abdulrasool ${ }^{*}$
} \\ *Department of Pharmaceutics, College of Pharmacy, University of Baghdad, Baghdad,Iraq.
}

\section{Abstract}

In recent years, observed focus greatly on gold nanoparticles synthesis due to its unique properties and tremendous applicability. In most of these researches, the citrate reduction method has been adopted. The aim of this study was to prepare and optimize monodisperse ultrafine particles by addition of reducing agent to gold salt, as a result of seed mediated growth mechanism. In this research, gold nanoparticles suspension (G) was prepared by traditional standard Turkevich method and optimized by studying different variables such as reactants concentrations, preparation temperature and stirring rate on controlling size and uniformity of nanoparticles through preparing twenty formulas (G1-G20). Subsequently, the selected formula that prepared from the best tested condition was further optimized by preparing it using inverse method via the addition of gold salt to the reducing agent in opposite to the previous traditional method $(\mathrm{G} 21)$. The optimized gold nanoparticles were characterized by SEM, EDX, TEM and zeta potential. The obtained results indicated that (G21) with reactants concentrations of $0.5 \mathrm{mM}$ and $10 \mathrm{mM}$ for $\mathrm{HAuCl}_{4} \cdot 3 \mathrm{H}_{2} \mathrm{O}$ and trisodium citrate dihydrate respectively, $65^{\circ} \mathrm{C}$ of preparation temperature and 1500rpm of stirring rate was chosen as an optimized formula according to AFM provided gold nanoparticles with smoother surface, smaller size (average $8.75 \mathrm{~nm}$ ) with more uniform size distribution (7.32\%) as well as short over all preparation time (27minutes). In addition to that all results of SEM, EDX and TEM indicated uniform spherical shape with zeta potential of -47.87 . Gelatin was used to enhance the colloidal stability. Three formulas of etoposide-loaded gold nanoparticles were prepared using different initial loading of etoposide. Formula (F1) was prepared from $5 \mathrm{mg} / \mathrm{ml}$ etoposide solution which gave higher loading efficiency $(91.73 \%$ ) and in-vitro released with controlled manner (better retardation at physiological $\mathrm{pH} \sim 7.4$ and greater release at lysosomal $\mathrm{pH} \sim 4.6$ ) as well as AFM results provided gold nanoparticles with smoother surface, average particles size $(22.74 \mathrm{~nm})$ with uniform size distribution $(20.73 \%)$. In conclusion, inversed method is promising for the preparation of gold nanoparticles with high monodispersity.

Keywords: Gold nanoparticles, Etoposide, Classical and inversed citrate reduction method.

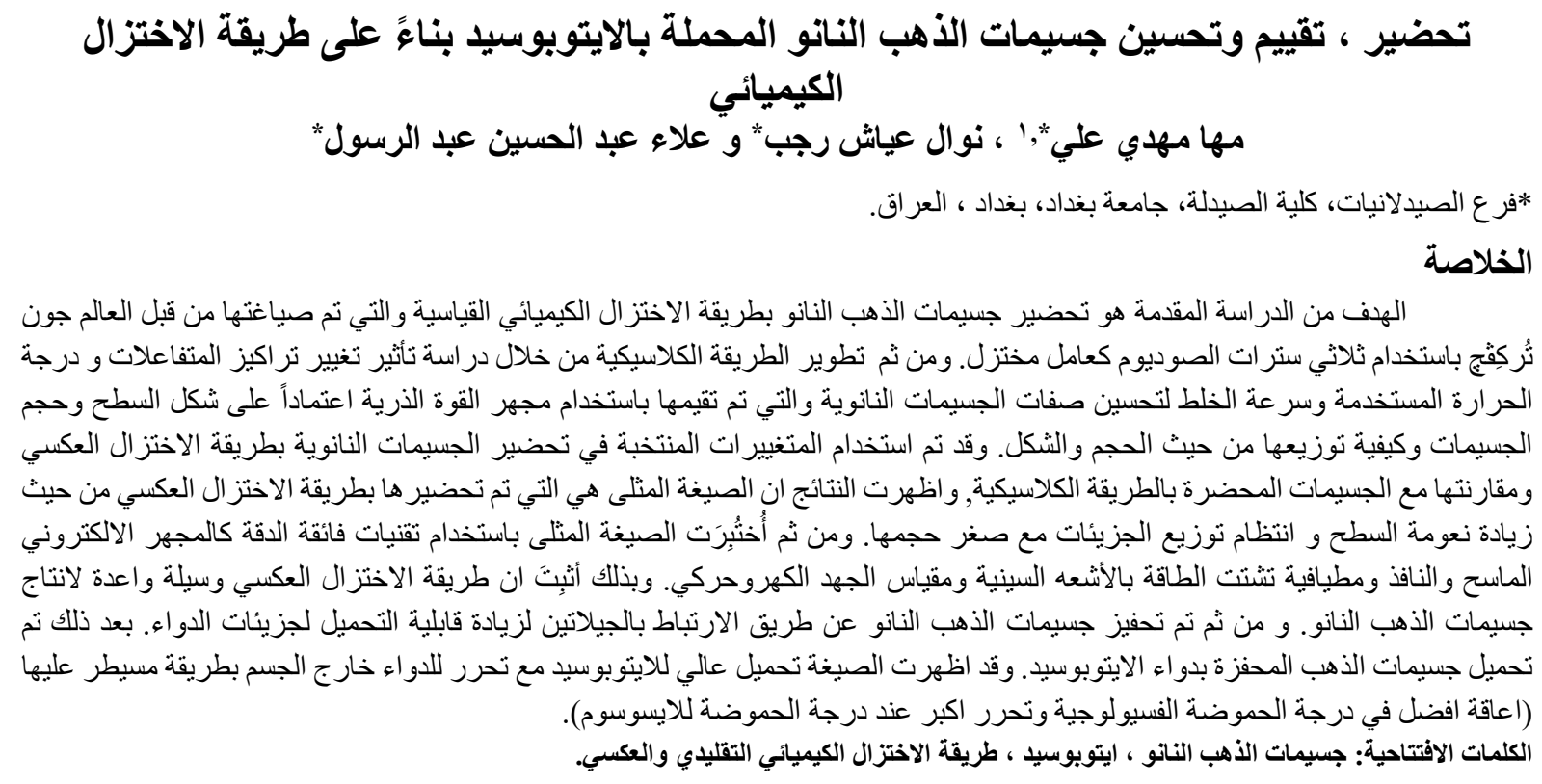

${ }^{1}$ Corresponding author E-mail: mahamahdi2020@gmail.com

Received: 29/ 12/2019

Accepted: $20 / 5 / 2020$

Iraqi Journal of Pharmaceutical Science 


\section{Introduction}

The most emerging branch in pharmaceutical sciences known as "pharmaceutical nanotechnology" presents new tools, opportunities and scope, which are expected to have significant applications in disease diagnostics and therapeutics. Various researches are currently working on nanoparticles especially in metal nanoparticles and further more specifically in gold nanoparticles ${ }^{(1)}$. Recently metal nanoparticles are universally considered as promising multifunctional platforms for wide purposes particularly in the case of cancer and gene diseases. Since, gold nanoparticles reveal enormous potential in drug delivery as carrier for spatial and temporal delivery of bioactive and diagnostic $^{(2)}$.

Gold nanoparticles has gained increasing importance in pharmaceutical nanotechnology owing to their special features, such as tunable their size and shape, strong absorption and scattering properties, easy surface functionalization, simple set up for synthesizing and high biological stability and compatibility ${ }^{(3)}$. Thus, a lot of volume of researches focuses on synthesis techniques of gold nanoparticles, including chemical, thermal, electrochemical, sonochemical and photochemical reduction pathways. Among all these methods, the citrate reduction; pioneered by John Turkevich in 1951 , is one of the most broadly used techniques ${ }^{(4 ;}$ 5).

Until today, the protocol of original synthesis was numerous times modified allowing synthesis of nanoparticles in wide sizes range. The monodispersed gold nanoparticles with desired size and morphology can be obtained depending on the seed mediated growth mechanism. In this classical technique, a trisodium citrate dihydrate solution was quickly added to a preheated solution of hydrogen tetrachloroaurate trihydrate. Since, citrate acts as poor reducing and stabilizing agent. In contrast, the inversed method designed by sirvaraman et al. comprises change the order of reactants addition leads to formation of stronger reducing and stabilizing agent (dicarboxy acetone) by induced thermal oxidation of trisodium citrate dihydrate ${ }^{(6 ; 7)}$.
The aim of the present study was to develop gold nanoparticles with high size and shape uniformity in order to improve their ability as drug carrier.

\section{Materials and Methods Materials}

Etoposide powder (98-105\%), Hydrogen tetrachloroaurate trihydrate $\left(\mathrm{HAuCl}_{4} .3 \mathrm{H}_{2} \mathrm{O}>99 \%\right)$ and trisodium citrate dihydrate $\left(\mathrm{Na}_{3} \mathrm{C}_{6} \mathrm{H}_{5} \mathrm{O}_{7} .2 \mathrm{H}_{2} \mathrm{O}>99 \%\right)$ were supplied from Sigma Aldrich Company, USA. Gelatin was obtained from Medichem Enterprice Co. Limited, China. All other ingredients used in the study were analytical grade.

\section{Methods}

\section{Preparation of gold nanoparticles by standard} turkevich method

Gold nanoparticles suspension (G) was prepared by standard chemical reduction method; proposed by Turkevich. The gold $\left(\mathrm{HAuCl}_{4} \cdot 3 \mathrm{H}_{2} \mathrm{O}\right)$ solution used as precursor while the citrate $\left(\mathrm{Na}_{3} \mathrm{C}_{6} \mathrm{H}_{5} \mathrm{O}_{7} .2 \mathrm{H}_{2} \mathrm{O}\right)$ solution used as a mild reducing, $\mathrm{pH}$ mediating, stabilizing and capping agent, as demonstrated in Table 1.

A volume of $1 \mathrm{ml}$ of gold solution $(50 \mathrm{mM})$ was diluted with $198 \mathrm{ml}$ of preheated deionized water (DW) in a tightly closed conical flask on hot plate magnetic stirrer. The solution was gently stirred manually for 15 minuts using glass rod stirrer at $75^{\circ} \mathrm{C}$. Then after, $1 \mathrm{ml}$ of citrate solution $(500 \mathrm{Mm})$ was quickly transferred (the final concentration was $2.5 \mathrm{mM}$ ) with continuous stirring at a constant temperature until a characteristic red color was observed, indicating for the formation of gold nanoparticles. Subsequently, the heating was switched off and the suspension was allowed to cool at room temperature with continuous stirring, then filtered using $0.1 \mu \mathrm{m}$ syringe-filter to remove any possible aggregates or dust impurities and stored in refrigerator at $2-8^{\circ} \mathrm{C}$ in a tightly closed dark container coated by aluminum foil, in order to quench any further reaction might be occurred due to light or temperature effects, prior to further characterization $^{(5-8)}$. 
Table 1. Composition of the gold nanoparticles suspensions using different preparation temperature, stirring rate and method.

\begin{tabular}{|c|c|c|c|c|c|c|}
\hline \multirow[t]{2}{*}{ Sample code } & \multicolumn{2}{|c|}{$\begin{array}{c}\text { Final molar } \\
\text { concentration } \\
(\mathrm{mm})\end{array}$} & \multirow[t]{2}{*}{$\begin{array}{l}\text { Volume of } \\
\text { gold stock } \\
\text { solution }(\mathrm{ml})\end{array}$} & \multirow[t]{2}{*}{$\begin{array}{c}\text { Volume of } \\
\text { citrate stock } \\
\text { solution }(\mathrm{ml})\end{array}$} & \multirow[t]{2}{*}{$\begin{array}{c}\text { Total } \\
\text { volume }(\mathrm{ml})\end{array}$} & \multirow[t]{2}{*}{ Preparation temperature } \\
\hline & HAUC14 & Citrate & & & & \\
\hline $\mathrm{G}^{\bullet}$ & 0.25 & 2.5 & 1 & 1 & 200 & $75^{\circ} \mathrm{C}$ \\
\hline G1 & 0.0625 & 2.5 & 0.25 & 1 & 200 & $75^{\circ} \mathrm{C}$ \\
\hline G2 & 0.125 & 2.5 & 0.5 & 1 & 200 & $75^{\circ} \mathrm{C}$ \\
\hline G3 & 0.5 & 2.5 & 2 & 1 & 200 & $75^{\circ} \mathrm{C}$ \\
\hline G4 & 1 & 2.5 & 4 & 1 & 200 & $75^{\circ} \mathrm{C}$ \\
\hline G5 & 2 & 2.5 & 8 & 1 & 200 & $75^{\circ} \mathrm{C}$ \\
\hline G6 & 0.5 & 0.25 & 2 & 0.1 & 200 & $75^{\circ} \mathrm{C}$ \\
\hline G7 & 0.5 & 0.5 & 2 & 0.2 & 200 & $75^{\circ} \mathrm{C}$ \\
\hline G8 & 0.5 & 5 & 2 & 2 & 200 & $75^{\circ} \mathrm{C}$ \\
\hline G9 & 0.5 & 10 & 2 & 4 & 200 & $75^{\circ} \mathrm{C}$ \\
\hline G10 & 0.5 & 20 & 2 & 8 & 200 & $75^{\circ} \mathrm{C}$ \\
\hline G11 & 0.5 & 10 & 2 & 4 & 200 & Room temperature \\
\hline G12 & 0.5 & 10 & 2 & 4 & 200 & $45^{\circ} \mathrm{C}$ \\
\hline G13 & 0.5 & 10 & 2 & 4 & 200 & $55^{\circ} \mathrm{C}$ \\
\hline G14 & 0.5 & 10 & 2 & 4 & 200 & $65^{\circ} \mathrm{C}$ \\
\hline G15 & 0.5 & 10 & 2 & 4 & 200 & $85^{\circ} \mathrm{C}$ \\
\hline G16 ${ }^{(1)}$ & 0.5 & 10 & 2 & 4 & 200 & $65^{\circ} \mathrm{C}$ \\
\hline $\mathrm{G} 17^{(2)}$ & 0.5 & 10 & 2 & 4 & 200 & $65^{\circ} \mathrm{C}$ \\
\hline G18 ${ }^{(3)}$ & 0.5 & 10 & 2 & 4 & 200 & $65^{\circ} \mathrm{C}$ \\
\hline $\mathrm{G} 19^{(4)}$ & 0.5 & 10 & 2 & 4 & 200 & $65^{\circ} \mathrm{C}$ \\
\hline $\mathrm{G} 20^{(5)}$ & 0.5 & 10 & 2 & 4 & 200 & $65^{\circ} \mathrm{C}$ \\
\hline $\mathrm{G} 21^{\triangleleft \diamond}$ & 0.5 & 10 & 2 & 4 & 200 & $65^{\circ} \mathrm{C}$ \\
\hline
\end{tabular}

Prepared by standard Turkevich method ${ }^{\bullet}$ Prepared by inversed method. Stirring rate (1) 500rpm(2) 750rpm (3) $1000 \mathrm{rpm}$ (4) $1250 \mathrm{rpm}$ (5) $1500 \mathrm{rpm}$

\section{Characterization of gold nanoparticles $(G)$ qualitative dispersibility measurements}

The simplest inexpensive approaches that confirm the presence of spherical gold nanoparticles are:

\section{Visual appearance}

The sample was visually inspected for color, clarity, transparency, glossiness, and homogenecity. Laser pointer test

The test was done by shining a laser pointer light into the sample, which put in a glass test tube. Salt test

$\mathrm{NaCl}$ solution $10 \%$ w/v was added drop by drop to a test tube containing $3 \mathrm{ml}$ of sample. The electrolytes change the optical properties of gold nanoparticles significantly ${ }^{(9)}$.

\section{$U V$-Visible spectrum analysis}

UV-Visible analysis is a specialized technique confirms presence of gold nanoparticles. The shape of absorption spectrum varies in different shapes and sizes of gold nanoparticles, usually gold nanospheres give a single absorption peak between 515-550nm depending on their particles diameter. Gold nanoparticles with shape rather than spherical gave another peak greater than $600 \mathrm{~nm}$. The relative uniformity of nanoparticles can be gauged by the full width of half maximum (FWHM) ${ }^{(9 ; 10)}$.

\section{Atomic Force Microscopy Measurement (AFM)}

The AFM analysis allows for three dimensions (3D) characterization of gold nanoparticles with sub-nanometer resolution provides both qualitative and quantitative information about morphology, size, and size distribution. The sample was prepared by dropletevaporation method; $100 \mu \mathrm{l}$ of suspension was diluted with $900 \mu \mathrm{l}$ of DW and sonicated for 15 minutes, then filtered using $0.1 \mu \mathrm{m}$ syringe-filter. A droplet of sample was deposited on silica glass slide and leave to dry overnight at room temperature in a light and dust protected environment ${ }^{(10 ; 11)}$. 


\section{Optimization of gold nanoparticles}

Different preparation parameters (Table 1) were studied to produce high quality gold nanoparticles with desired morphology, size, and size distribution, based on AFM analysis.

\section{Effect of $\mathrm{HAuCl}_{4} 3 \mathrm{H}_{2} \mathrm{O}$ concentration}

Five suspensions (G1-5) were prepared by classical citrate reduction method, using different final molar concentration of $\mathrm{HAuCl}_{4} .3 \mathrm{H}_{2} \mathrm{O}(0.0625$, $0.125,0.5,1$, and $2 \mathrm{mM}$, respectively), at a fixed citrate concentration, and compared to standard suspension $(\mathrm{G})$ with $0.25 \mathrm{Mm} \mathrm{HAuCl}_{4} .3 \mathrm{H}_{2} \mathrm{O}$ to choose the best one for further studies.

\section{Effect of $\mathrm{Na}_{3} \mathrm{C}_{6} \mathrm{H}_{5} \mathrm{O}_{7} .2 \mathrm{H}_{2} \mathrm{O}$ concentration}

Five suspensions (G6-10) were prepared using different final molar concentration of $\mathrm{Na}_{3} \mathrm{C}_{6} \mathrm{H}_{5} \mathrm{O}_{7} .2 \mathrm{H}_{2} \mathrm{O} \quad(0.5, \quad 1, \quad 5,10$, and $20 \mathrm{mM}$, respectively), and compared to suspension prepared with previously selected $\mathrm{HAuCl}_{4} .3 \mathrm{H}_{2} \mathrm{O}$ concentration and $2.5 \mathrm{mM} \mathrm{Na} \mathrm{Na}_{6} \mathrm{H}_{5} \mathrm{O}_{7} .2 \mathrm{H}_{2} \mathrm{O}$, to choose the best one for further studies.

\section{Effect of preparation temperature}

Five suspensions (G11-15) were prepared, under different temperature (room temperature, $45^{\circ} \mathrm{C}, 55^{\circ} \mathrm{C}, 65^{\circ} \mathrm{C}$, and $85^{\circ} \mathrm{C}$ respectively), and compared with selected suspension prepared at $75^{\circ} \mathrm{C}$ to choose the best temperature for further studies.

\section{Effect of stirring rate}

Five suspensions (G16-19) were prepared, under different stirring rate $(500,750,1000,1250$, and $1500 \mathrm{rpm}$ respectively), and compared with selected suspension prepared under gentile stirring by glass rod stirrer to choose the best stirring rate for further studies.

\section{Effect of reactants addition order}

G21 suspension with the desired final molar concentration of $\mathrm{HAuCl}_{4} .3 \mathrm{H}_{2} \mathrm{O} \quad(0.5 \mathrm{mM})$ and $\mathrm{Na}_{3} \mathrm{C}_{6} \mathrm{H}_{5} \mathrm{O}_{7} .2 \mathrm{H}_{2} \mathrm{O} \quad(10 \mathrm{mM})$, under the selected preparation temperature $\left(65^{\circ} \mathrm{C}\right)$ and stirring rate $(1500 \mathrm{rpm})$, were prepared by inversed the classical method, corresponds to addition of small volume $(2 \mathrm{ml})$ of highly concentrated $(50 \mathrm{mM})$ gold solution to large volume (198ml) of diluted citrate solution in order to study the effect of change the order of reactants addition on the morphology, size, and distribution to choose the optimized gold nanoparticles suspension ${ }^{(7 ; 12)}$.

Characterization of the optimized gold nanoparticles for colloidal stability, elemental composition, surface morphology and particles, shape, size and distribution

Zeta potential measurement

Zeta potential has important indicant about dispersion stability in water. Typically, gold nanoparticles with zeta potential greater than $+20 \mathrm{mV}$ or less than $-20 \mathrm{mV}$ have sufficient electrostatic repulsion between neighboring correspondingly charged particles to remain stable in their suspension. The sample was prepared by diluted $100 \mu \mathrm{l}$ of suspension with $10 \mathrm{ml}$ of DW then filtered using $0.1 \mu$ l syringe-filter ${ }^{(13)}$.

Scanning Electron Microscopy (SEM)

SEM technique gives detailed high resolution 3D image, has high accuracy and reliability for determining the size, size distribution and morphology of gold nanoparticles. The sample was prepared by drop-casting method; One drop of suspension was deposited on silica glass slide and leave to dry at room temperature in a light and dust protected environment, then another drop of sample deposited and continue until dense dry layer was formed, then scanned at different magnification ${ }^{(14 ;}$ 15).

\section{Energy Dispersive X-Ray Spectroscopy (EDX)}

EDX provides elemental identification and quantitative compositional information for gold nanoparticles. The sample was prepared by dropcasting method, as mentioned previously ${ }^{(16)}$.

Transmission Electron Microscopy (TEM)

TEM provides a much magnified high resolution two direction (2D) image, which interprets the exact shape and size of gold nanoparticles. One drop of sample was placed on a 400 mesh carbon coated copper grid by an ultramicrometry process and scanned at different magnification ${ }^{(17 ; 18)}$.

\section{Functionalization of gold nanoparticles}

The optimized gold nanoparticles were functionalized by bio-conjugation method, using gelatin as a biocompatible polymer. Firstly, gelatin solution was prepared by mixing $300 \mathrm{mg}$ of polymer with $10 \mathrm{ml}$ of deionized water for 3hours using magnetic stirrer at $1500 \mathrm{rpm}$. Then after, the polymeric-gold nanoparticles suspension was prepared by mixing $1 \mathrm{ml}$ of gelatin solution with $10 \mathrm{ml}$ of the optimized gold nanoparticles suspension, in a tightly closed conical flask, for 1 hour at room temperature and $1500 \mathrm{rpm}$; and sonicated for 6hours. Then filtered using $0.1 \mu \mathrm{m}$ syringe-filter to remove the unconjugated polymer and any possible aggregates, and stored in refrigerator at $2-8^{\circ} \mathrm{C}$ in a tightly closed dark container coated by aluminum foil ${ }^{(10,19)}$.

AFM measurement was used to infer the binding of polymer layer on the surface of gold nanoparticles and conclude about the stability of bio-conjugate as well as to evaluate the effect of polymer on the gold nanoparticles growth and morphology.

\section{Incorporation of etoposide}

Firstly the stock solution of etoposide was prepared by dissolving $0.15 \mathrm{gm}$ of etoposide powder in $0.5 \mathrm{ml}$ of dimethyl sulfoxide ( (DMSO) and completed to $10 \mathrm{ml}$ by buffer solution of $(\mathrm{pH} 10.5)$, sonicated for about 3hours at room temperature till a clear solution was obtained.

Etoposide-loaded gold nanoparticles suspensions were prepared by adding $1 \mathrm{ml}$ of 
etoposide solution at a calculated concentration ( 5 , 10 or $15 \mathrm{mg} / \mathrm{ml}$ for $\mathrm{F} 1-\mathrm{F} 3$, respectively) to $9 \mathrm{ml}$ of polymeric gold nanoparticles suspension, in a tightly closed conical flask, and mixed for 1 hour on a hot plate magnetic stirrer at $55^{\circ} \mathrm{C}$ and $1500 \mathrm{rpm}$, then sonicated for 5hours until achieved a clear transparent suspension, and stored in refrigerator at $2-8^{\circ} \mathrm{C}$ in a tightly closed dark container coated by aluminum foil, prior to further characterization $(19,20)$.

AFM measurement was used to evaluate the effect of initial etoposide loading on nanoparticles size, distribution and morphology.

\section{Evaluation of etoposide loading efficiency}

$0.5 \mathrm{ml}$ of etoposide-loaded gold nanoparticles suspension was centrifuged with Amicon filter of $3 \mathrm{KDa} / \mathrm{MWCO}$, at $6000 \mathrm{rpm}$ for 20 minutes. The amount of free etoposide was determined by UVVisible measurement, and then calculated the etoposide loading efficiency by the following equation:

$$
L E_{\%}=\frac{D_{0}-D_{f}}{D_{0}} \times 100 \%
$$

Where $L E_{\%}$ is the percentage of drug loading efficiency, $D_{0}$ is the total amount of drug fed in formula and $D_{f}$ is the amount of free drug leak through Amicon filter ${ }^{(21,22)}$.

\section{Evaluation of in-vitro etoposide release}

$2 \mathrm{ml}$ of etoposide-loaded gold nanoparticles suspension was added into cellulose diffusion dialysis tubing of $12 \mathrm{KDa} / \mathrm{MWCO}$; both ends were tied, and immerged in a dissolution jar filled with $500 \mathrm{ml}$ of dissolution media at a constant temperature $\left(37 \pm 1^{\circ} \mathrm{C}\right)$ and rotated at $100 \mathrm{rpm}$. Samples of $3 \mathrm{ml}$ were withdrawn at predetermined time intervals of $0.25,0.5,0.75,1,1.5,2,3,4,5,10$, 15, 20 and 24hours; and replaced each time immediately with equal volume of the fresh dissolution media to maintain constant volume. The samples were analyzed for etoposide content using UV-Visible spectrophotometer. The percentage of drug released was calculated by the following equation:

$$
D_{\%}=\frac{D_{t}}{D_{0}} \times 100 \%
$$

Where $D \%$ is the percentage of drug release at time t, $D_{t}$ is the amount of drug release at certain time interval and $D_{0}$ is the total amount of drug fed in formula.

The pH-responsive capacity of etoposideloaded gold nanoparticles was investigated using two different dissolution media (phosphate buffer pH 7.4 and acetate buffer $\mathrm{pH} 4.6)^{(23,24)}$.

\section{Results and Discussion}

Citrate reduction method was a more straightforward procedure for gold nanoparticles preparation, as a result of seed mediated growth mechanism; illustrated in Figure 1.

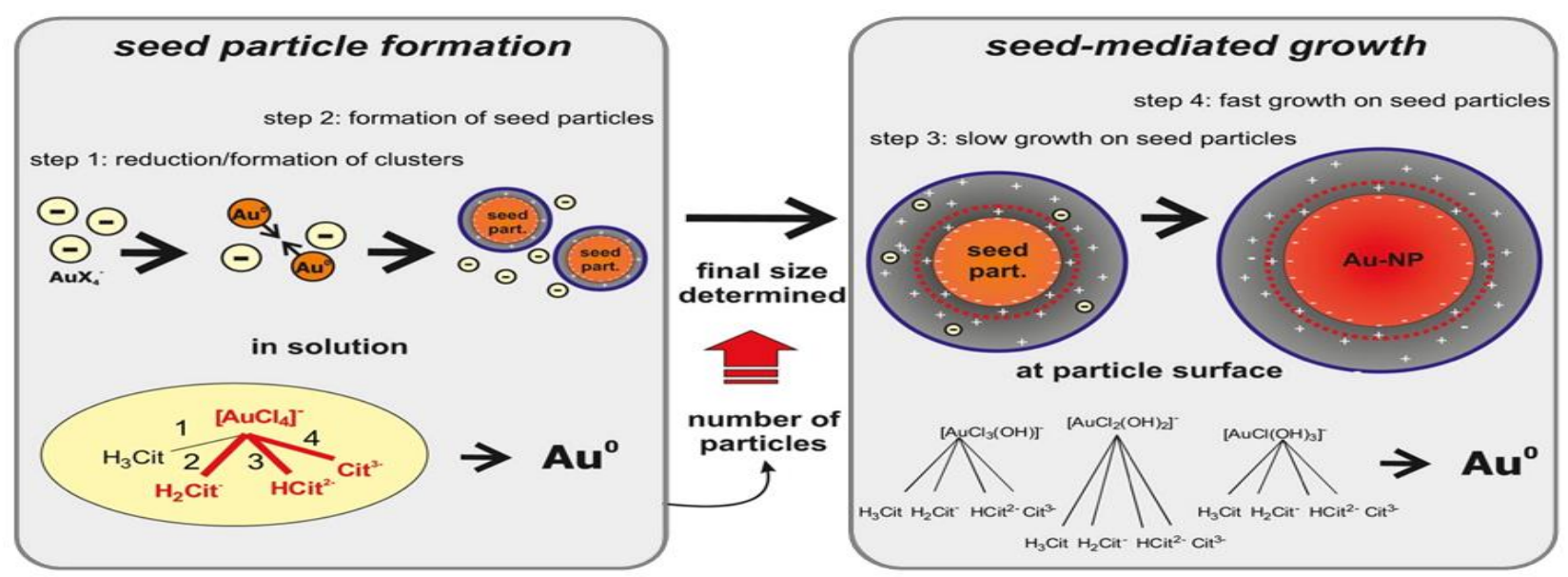

Figure 1. Gold nanoparticles formation by seed-mediated growth mechanism ${ }^{(12)}$

Citrate has three carboxyl groups, which can be protonated/deprotonated leading to an acid base buffer. In addition, citrate can be irreversibly oxidized to faster reducing agent (dicarboxy acetone). Citrate was interplay many chemical and physicochemical processes which initiate and also terminate of seed particles formation. While gold ions $\mathrm{Au}^{+3}$ exist in different chemical species which can be reversibly converted to each other as shown in the following reaction:

$$
\begin{gathered}
{\left[\mathrm{AuCl}_{4}\right]^{-1} \leftrightarrow\left[\mathrm{AuCl}_{3}(\mathrm{OH})\right]^{-1} \leftrightarrow\left[\mathrm{AuCl}_{2}(\mathrm{OH})_{2}\right]^{-1}} \\
\leftrightarrow\left[\mathrm{AuCl}(\mathrm{OH})_{3}\right]^{-1} \leftrightarrow\left[\mathrm{Au}(\mathrm{OH})_{4}\right]^{-1(25)}
\end{gathered}
$$

In first step of preparation; immediately after the addition of reducer, gold solution was discoloring instantly from faint yellow to colorless solution. This result was emerged due to a partial fast reduction of $\mathrm{Au}^{+3}$ and formation a small cluster 
from neutral gold monomers $\mathrm{Au}$, which initiate formation of seeds in the next step. As well as, initial $\mathrm{pH}$ (3.3) increased to about 6.5 upon addition of citrate solution, which shift the gold reaction equilibrium toward the less reactive species $\left[\mathrm{AuCl}_{3-}\right.$ $\left.\mathrm{x}(\mathrm{OH})_{1+\mathrm{x}}\right]$ that terminate uncontrolled excessive formation of seed particles. The balance between these two processes determines the final number of particles formed ${ }^{(26)}$.

After about five seconds, a light gray color starts to appear quickly because the solution became supersaturated with Au clusters. Then the solution color was turned into dark gray-bluish within about thirty seconds and gradually changed to purple. This result indicated the formation of stable seed particles with size more than $1.5 \mathrm{~nm}$ (consist about $840 \mathrm{Au}$ atoms). Subsequently, the remaining $\mathrm{Au}^{+3}$ attached as co-ions in an electronic double layer of seeds, leaded to change their electronic properties ${ }^{(27,28)}$.

At the last step of preparation; after about 28 minutes, a red color was beginning to appear. This step comprises the slow reduction of $\mathrm{Au}^{+3}$ until a full consumed of the precursor whereby the generated $\mathrm{Au}$ exclusively grew on the top of seed particle's surfaces ${ }^{(29)}$.

\section{Qualitative dispersibility measurements}

Gold nanoparticles suspension $(G)$ was clear, transparent, shiny, and homogeneous, with a characteristic red color. A visible red laser beam path was observed through suspension, which confirm the presence of suspended spherical gold nanoparticles; that was scattering the shorter wavelength light by Willis-Tyndall effect. The brightness of suspension indicated for particles distribution uniformity. As well as it gave a positive salt test; Sodium ions neutralized the surface charge of nanoparticles and subsequently, lose their mutual electrostatic repulsion and started to aggregate for larger nanoparticles, as a result their color changed from red to blue-purple. Upon addition an excess amount of $\mathrm{NaCl}$, a colorless solution with dark precipitate was observed, which mean absent of suspended nanoparticles by overcoming the colloidal stability ${ }^{(9)}$.

\section{$\boldsymbol{U}$-visible spectrum analysis}

UV-Visible curve (Figure 2) of gold nanoparticles $(G)$ had a single peak with maximum absorption at $525 \mathrm{~nm}$ and high size-sensitive regions confirmed the successful formation of spherical gold nanoparticles with size range of 20-30nm. The curve revealed a low shape-sensitive region with narrow FWHM indicated for particles distribution uniformity ${ }^{(18,30)}$.

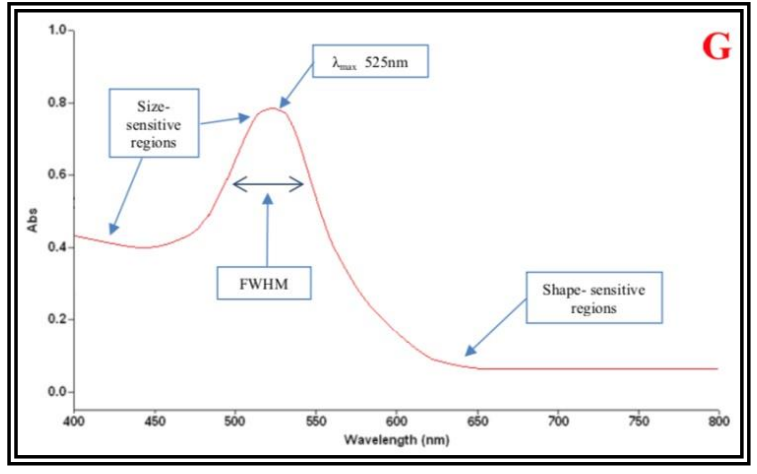

Figure 2. UV scan of gold nanoparticles (G)

\section{Atomic force microscopy measurement}

AFM 3D image (Figure 3) and particle size distribution (Figure 4) of gold nanoparticles (G) showed a smooth surface with fine particles distribution. The average particles size was $24.35 \mathrm{~nm}$ with distribution $23.98 \%$. These results supported the data of UV-Visible spectroscopy.

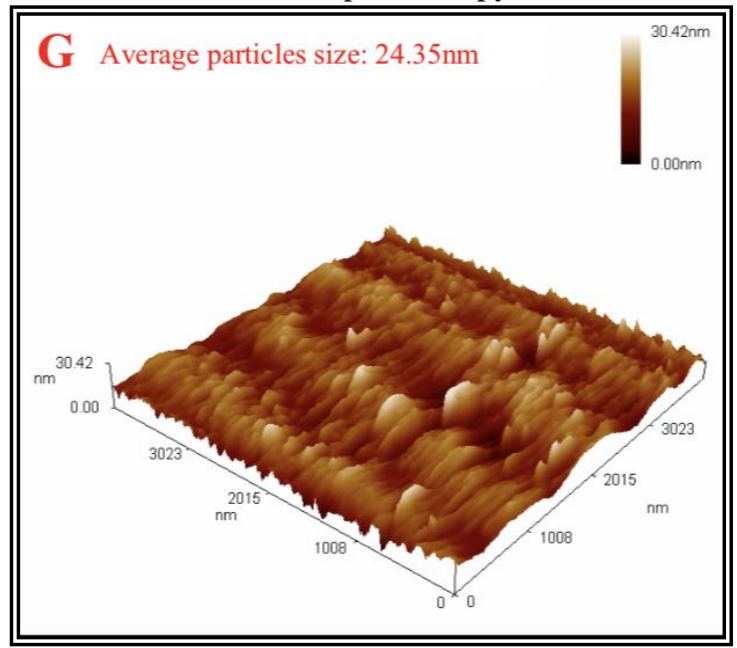

Figure 3. AFM 3D image of gold nanoparticles (G)

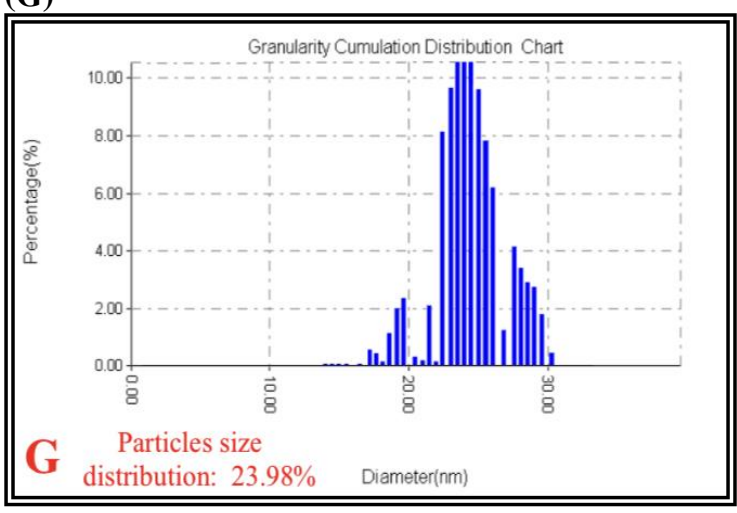

Figure 4. AFM size distribution of gold nanoparticles $(\mathbf{G})$

\section{Optimization of gold nanoparticles}

In this study, different variables had been studied for their effect on the prepared suspensions, in order to select the optimum gold nanoparticles that achieve the aim of our study. 


\section{Effect of $\mathrm{HAuCl}_{4} .3 \mathrm{H}_{2} \mathrm{O}$ concentration}

Gold nanoparticles G2, G, and G3 with $\mathrm{HAuCl}_{4} .3 \mathrm{H}_{2} \mathrm{O}$ concentration $0.125,0.25$ and $0.5 \mathrm{mM}$ respectively, showed a significant decreased $(p<0.05)$ in final nanoparticles size (Figure 5) and overall reaction time with increased $\mathrm{HAuCl}_{4} \cdot 3 \mathrm{H}_{2} \mathrm{O}$ concentration, while size distribution (Figure 6) was not significantly affected ( $>0.05)$ with this molar concentration limit. These results occurred because of $\mathrm{HAuCl}_{4} .3 \mathrm{H}_{2} \mathrm{O}$ concentration determined $\mathrm{pH}$ value of precursor solution and thereby ratio of gold chemical species during seed particles formation. G3 with higher $\mathrm{HAuCl}_{4} \cdot 3 \mathrm{H}_{2} \mathrm{O}$ concentration $(0.5 \mathrm{mM})$ and lower $\mathrm{pH}$ value (3), larger percentage of higher redox potential species $\left[\mathrm{AuCl}_{4}\right]^{-1}$ was available to provide more $\mathrm{Au}$ and form more seeds resulting in smaller final nanoparticles (average $19.63 \mathrm{~nm}$ ) with better size distribution (23.95\%). As well as shorter overall reaction time (23minutes), indicated that larger total surface area of seeds facilitated the kinetic of growth mechanism. G1 with very low $\mathrm{HAuCl}_{4} .3 \mathrm{H}_{2} \mathrm{O}$ concentration $(0.0625 \mathrm{mM})$ and initial $\mathrm{pH}$ value (4), gave larger nanoparticles with wide distribution, because the initial reactive species $\left[\mathrm{AuCl}_{4}\right]^{-1}$ was very low to trigger fast formation of seeds leaded to formation of less particles with uncontrolled growth ${ }^{(12 ; 31)}$.

G4 with $1 \mathrm{mM} \mathrm{HAuCl}_{4} .3 \mathrm{H}_{2} \mathrm{O}$ (initial $\mathrm{pH}=2.4$ ), A black precipitate was observing within few hours after preparation, which due to the buffering capacity of citrate was not sufficient to stop particles growth also the ionic strength which subsequently decreased the colloidal stability by increased the attractive van-der-walls force between particles. For gold nanoparticles G5 with $2 \mathrm{mM} \mathrm{HAuCl}_{4} \cdot 3 \mathrm{H}_{2} \mathrm{O}$ (initial $\mathrm{pH}=1.5$ ), the reduction of $\mathrm{Au}^{+3}$ was observed as converting yellow color of diluted gold solution to colorless, but only macro-sized particles were formed and precipitated at lab glass walls. This observation was explained by the effect of ionic strength that was vanished the colloidal stability. At higher concentration of $\mathrm{HAuCl}_{4} .3 \mathrm{H}_{2} \mathrm{O}$ more than $2 \mathrm{mM}$ (initial $\mathrm{pH}<1.5$ ), no reduction was observed and solution still has faint yellow color after addition of reducer. This happened due to the concentration of hydrogen ions $\mathrm{H}^{+}$exceeded the buffer capacity of citrate; which became full protonated by mixing with $\mathrm{HAuCl}_{4} \cdot 3 \mathrm{H}_{2} \mathrm{O}$. First step of seed-mediated growth mechanism required at least one deprotonated carboxyl group $(26 ; 27 ; 32)$.

G3 with best $\mathrm{HAuCl}_{4} \cdot 3 \mathrm{H}_{2} \mathrm{O}$ concentration $(0.5 \mathrm{mM})$ gave a better morphology, size, and size distribution was chosen for further optimization studies.

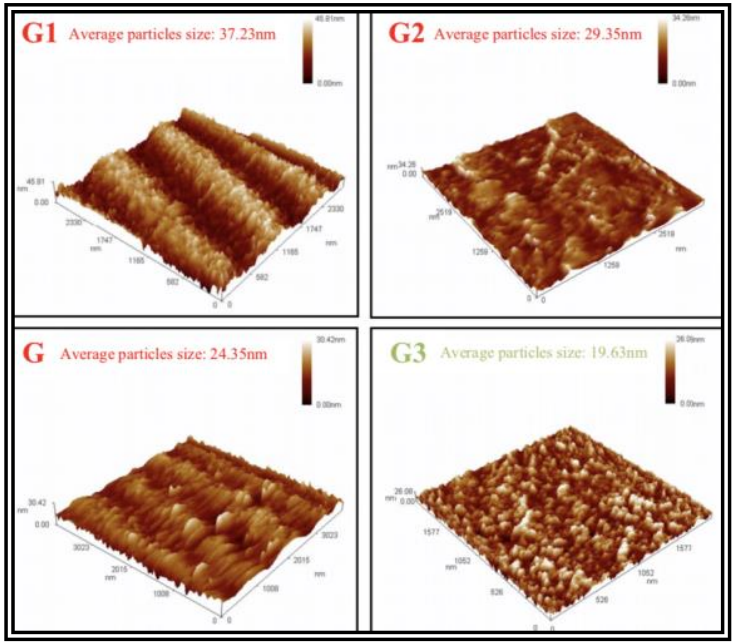

Figure 5: AFM 3D image of gold nanoparticles G, G1-3

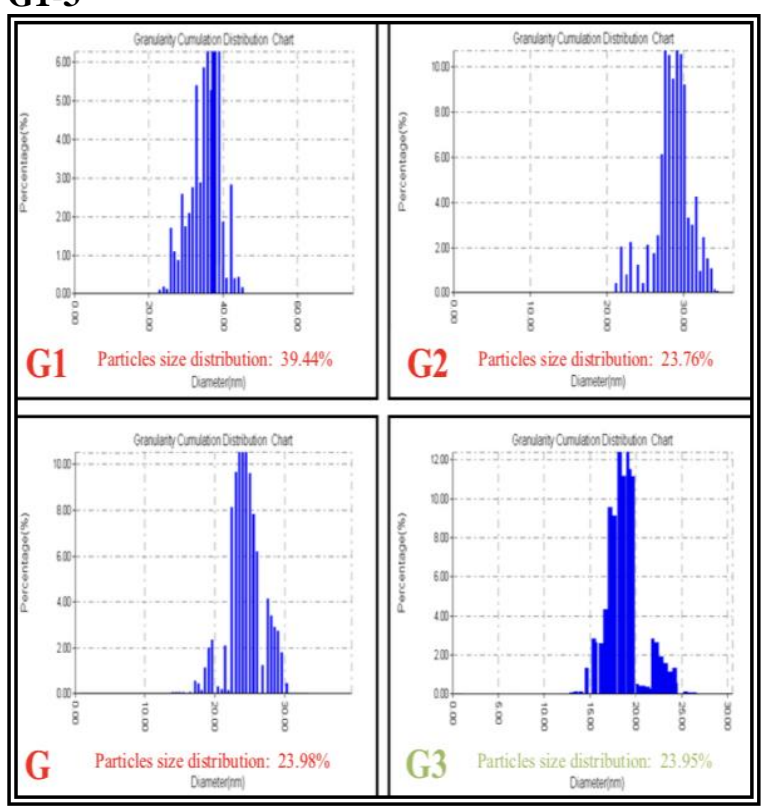

Figure 6: AFM size distribution of gold nanoparticles $\mathbf{G}, \mathbf{G 1 - 3}$

\section{Effect of $\mathrm{Na}_{3} \mathrm{C}_{6} \mathrm{H}_{5} \mathrm{O}_{7.2} \mathrm{H}_{2} \mathrm{O}$ concentration}

Gold nanoparticles G3 and G7-9 with sufficient concentration of $\mathrm{Na}_{3} \mathrm{C}_{6} \mathrm{H}_{5} \mathrm{O}_{7} .2 \mathrm{H}_{2} \mathrm{O}(0.5$ $10 \mathrm{mM})$ showed a significant decreased $(p<0.05)$ of particles size distribution (Figure 8) by increased citrate concentration, while nanoparticles size (Figure 7) remained almost non-significant affected (p>0.05) within this certain concentration limit. These results were happened due to the kinetic of the protonation equilibrium of citrate solution and the final neutral $\mathrm{pH}$ (about 6.5), which approximately the same irrespective to molar excess. G9 has better size distribution $(21.70 \%)$ indicated that the balance between gold and citrate concentration was reached ${ }^{(19)}$. G6 and G10 with very low $(0.25 \mathrm{mM})$ and very high $(20 \mathrm{mM})$ citrate concentrations respectively, gave larger nanoparticles (average $34.51 \mathrm{~nm}$ and $38.09 \mathrm{~nm})$ with wide distribution $(29.23 \%$ and $34.66 \%)$ respectively. The reasons for these results were the citrate concentration in G6 might still be 
sufficient to reduce $\mathrm{Au}^{+3}$ but not to shift gold complex equilibrium from $\left[\mathrm{AuCl}_{4}\right]^{-1}$ to less reactive hydrolyzed species, therefore seeds which still grew to reach colloidal stability. In contrast, in G10 the colloidal stability of seeds decreased due to increase the ionic strength leaded to larger final particles size with non-uniform distribution ${ }^{25 ; 33)}$.

G9 with best $\mathrm{Na}_{3} \mathrm{C}_{6} \mathrm{H}_{5} \mathrm{O}_{7} .2 \mathrm{H}_{2} \mathrm{O}$ concentration $(10 \mathrm{mM})$ gave a better morphology, size, and size distribution was chosen for further optimization studies.

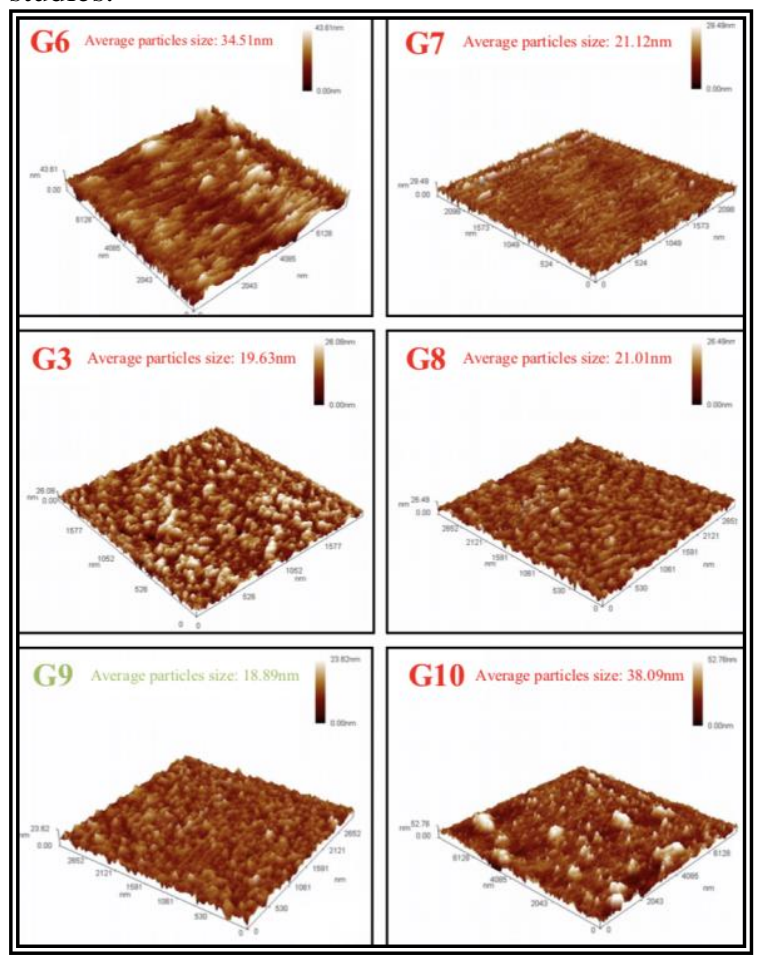

Figure 7. AFM 3D image of gold nanoparticles G3, G6-10

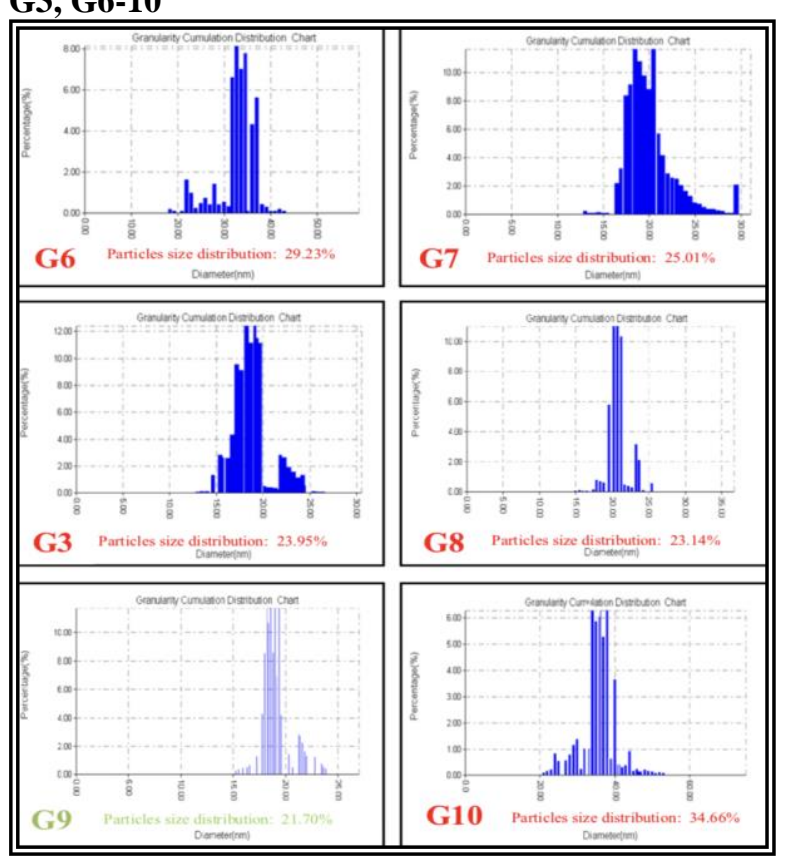

Figure 8. AFM size distribution of gold nanoparticles G3, G6-10

\section{Effect of preparation temperature}

AFM analysis (Figures 9-10) appeared a complex relationship between the preparation temperatures and gold nanoparticles size reduction. Firstly, the gold nanoparticles size and their distribution significantly decreased $(\mathrm{p}<0.05)$ with increased the preparation temperature (from room temperature to $65^{\circ} \mathrm{C}$ ), then the nanoparticles size and their distribution significantly increased $(\mathrm{p}<0.05)$ by increased the preparation temperature from $65-85^{\circ} \mathrm{C}$. This nonlinear temperature dependence happened due to the time frame of seeds formation became shorter by increased temperature, while the reactive $\left[\mathrm{AuCl}_{4}\right]^{-1}$ was faster reduced during an available time, also the elevated temperature promote shift of gold equilibrium toward more hydroxylated species $\left[\mathrm{Au}(\mathrm{OH})_{4}\right]^{-1}$. Because of these opposing tendencies, amount of $\mathrm{Au}$ available for seed formation would vary with temperature ${ }^{(12)}$. G14 prepared at $65^{\circ} \mathrm{C}$ gave smallest size (average $13.24 \mathrm{~nm}$ ) with best distribution $(18.90 \%)$ means at this temperature the balance between reducing and stabilizing activity of citrate was occurred. G11 prepared at room temperature gave larger nanoparticles (average $41.17 \mathrm{~nm}$ ) with bad distribution (42.63\%), because at this temperature the reaction takes about 2 days, without formation of dicarboxy acetone, thereby very slow reduction of $\mathrm{Au}^{+3}$ at initial phase of preparation, leaded to produce too few $\mathrm{Au}$ monomers for seeds formation and lastly larger particles was formed with uncontrolled growth mechanism ${ }^{(7 ; 34 ; 35)}$.

G14 prepared under best temperature $65^{\circ} \mathrm{C}$ gave a better morphology, size, and size distribution was chosen for further optimization studies.

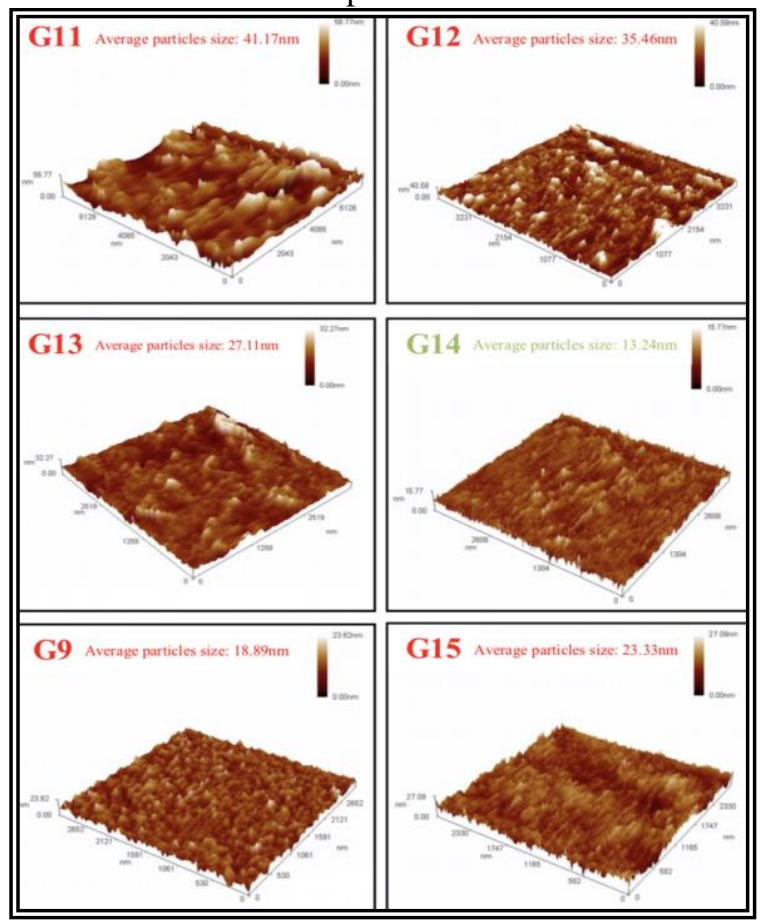

Figure 9. AFM 3D image of gold nanoparticles G9, G11-15 


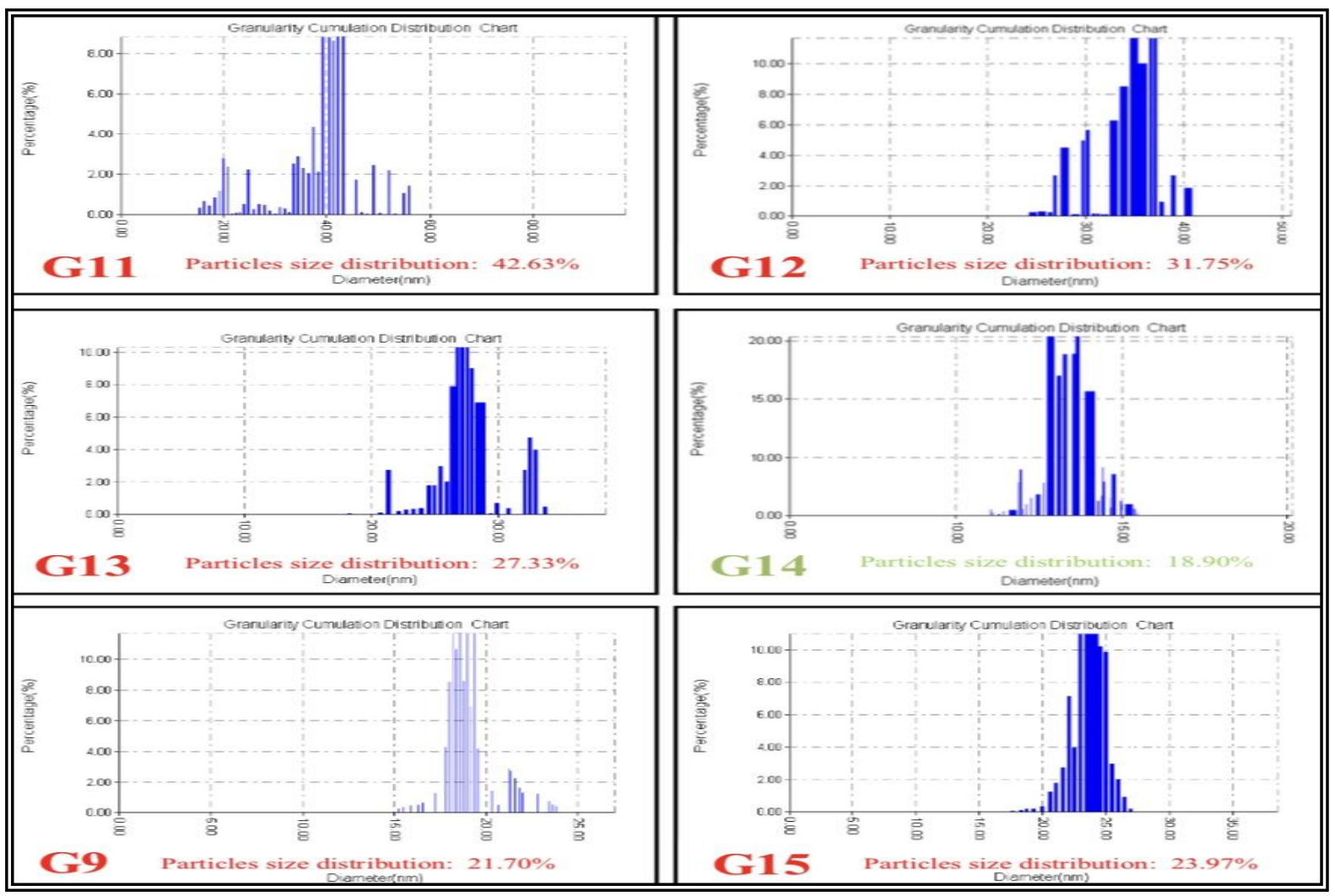

Figure 10. AFM size distribution of gold nanoparticles G9, G11-15

\section{Effect of stirring rate}

The gold nanoparticles size (Figure 11) was not significantly affected ( $>0.05)$ by changed the stirring rate, while their size distribution (Figure 12) as well as the overall reaction time were decreased significantly $(\mathrm{p}<0.05)$ with increased the stirring rate $^{(36)}$.

G20 with vigorous stirring rate of 1500rpm gave a best average particles size $(13.05 \mathrm{~nm})$, and their distribution (12.47\%) was chosen for further optimization studies.

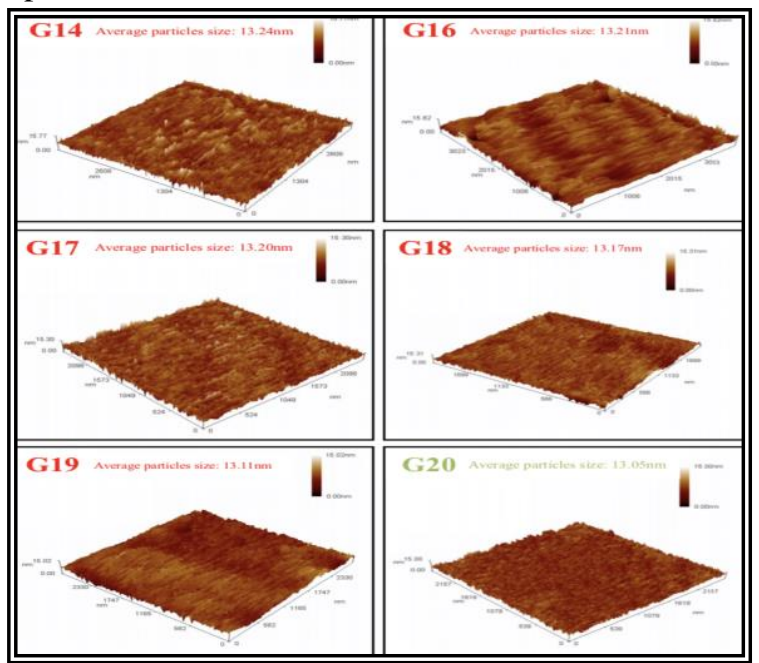

Figure 11. AFM 3D image of gold nanoparticles G14, G16-20

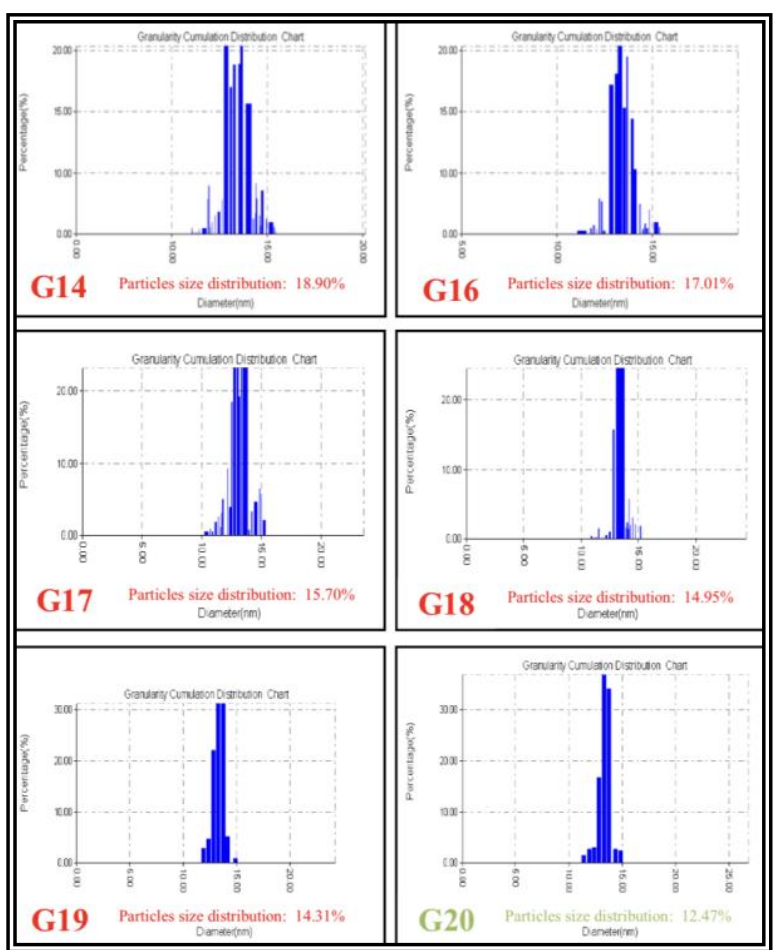

Figure 12. AFM size distribution of gold nanoparticles G14, G16-20

\section{Effect of reactants addition order}

G21 was prepared by inversed citrate reduction method and determined the effect of change the reactants addition order via comparing 
with G20, which prepared by the classical method. AFM analysis (Figure 13-14) indicated that the morphology, particles size, and distribution were improved significantly $(\mathrm{p}<0.05)$ when prepared the gold nanoparticles by inversed method. This improvement attributed to formation of dicarboxy acetone via thermal oxidation of citrate during preheating of diluted reducer solution, which acts as a kinetically faster reducer and strong stabilizer during initial phase of reaction. In addition, $\mathrm{HAuCl}_{4} .3 \mathrm{H}_{2} \mathrm{O}$ concentration was very high $(50 \mathrm{Mm})$ in the inverse method this provided presence of more $\left[\mathrm{AuCl}_{4}\right]^{-1}$ during seeds formation. Subsequently, more $\mathrm{Au}$ monomers were available and more seeds formed, which leaded to produce smaller gold nanoparticals (average $8.75 \mathrm{~nm}$ ) with more uniform size distribution $(7.32 \%)$ as well as short over all preparation time $(27 \text { minutes })^{(7 ; 25 ; 37)}$.

From all these studies, G21 considered as the optimized gold nanoparticles suspension.

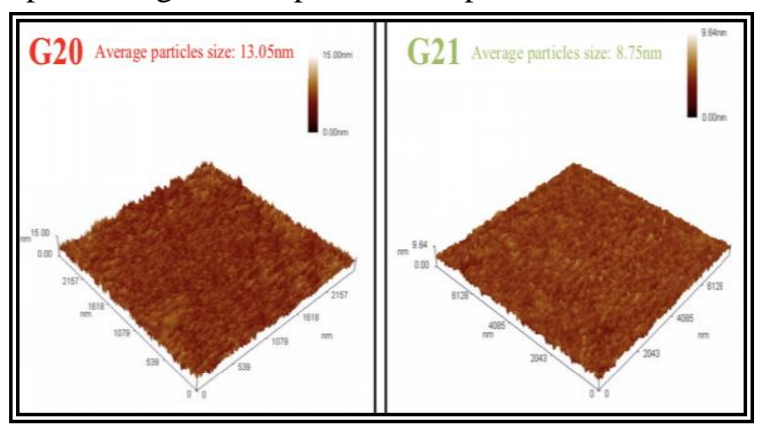

Figure 13. AFM 3D image of gold nanoparticles G20-21

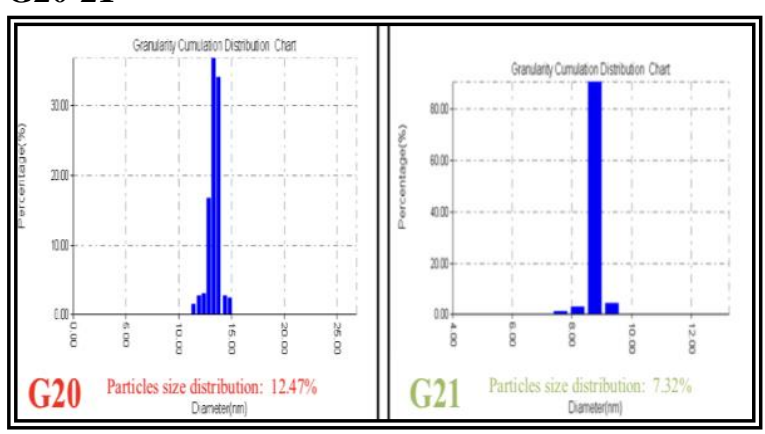

Figure 14. AFM size distribution of gold nanoparticles G20-21

\section{Zeta potential measurement}

Zeta potential is an important pointer of steadiness the gold colloidal dispersion. For the optimized suspension G21; with nanoparticles which small enough, a highly negative zeta potential of -47.87 (Figure 15) gave a steadiness, therefore the suspension would be struggle against aggregation due to a strange repellent force between particles. The reason behind negative charge was the citrate ions at the surface of nanopaticles ${ }^{(38)}$.

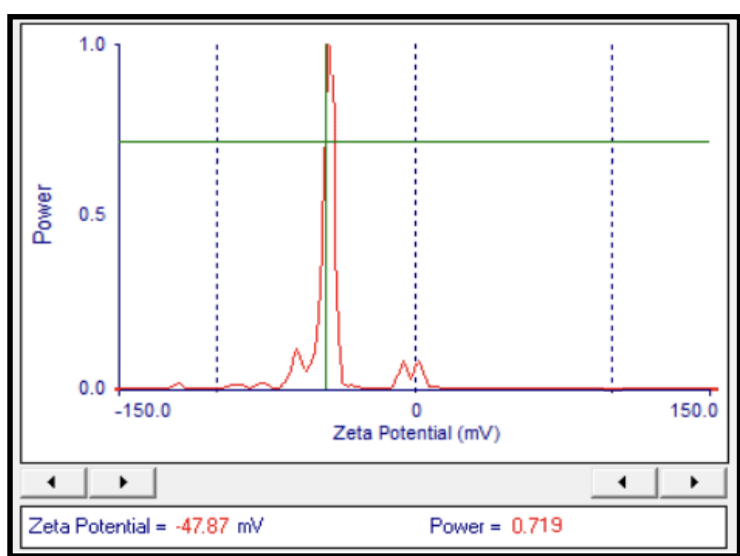

Figure 15. Zetapotential monograph of the optimized gold nanoparticles G21

\section{Scanning electron microscopy}

The optimized suspension G21 was examined by SEM at different magnifications and the nanoparticles only appeared at higher magnification $50 \mathrm{Kx}$ with spatial resolution of 500nm.

SEM image (Figure 16) revealed gold nanoparticles with uniform shiny spherical shape and smooth surface that consistently dispersed on the surface ${ }^{(18)}$. nanoparticles size measured by SEM (average $8.96 \mathrm{~nm}$ ) was not significantly differed $(\mathrm{p}>0.05)$ than the data of AFM analysis (average $8.75 \mathrm{~nm})$.

The comparison of particles size distribution measured by AFM and SEM indicated that wider distribution (10.79\%) when measured via SEM than AFM (7.32\%), this result was most likely artifacts formed during SEM sample preparation (drying at room temperature take about 1week) and do not represent actual properties of gold nanoparticles G21.

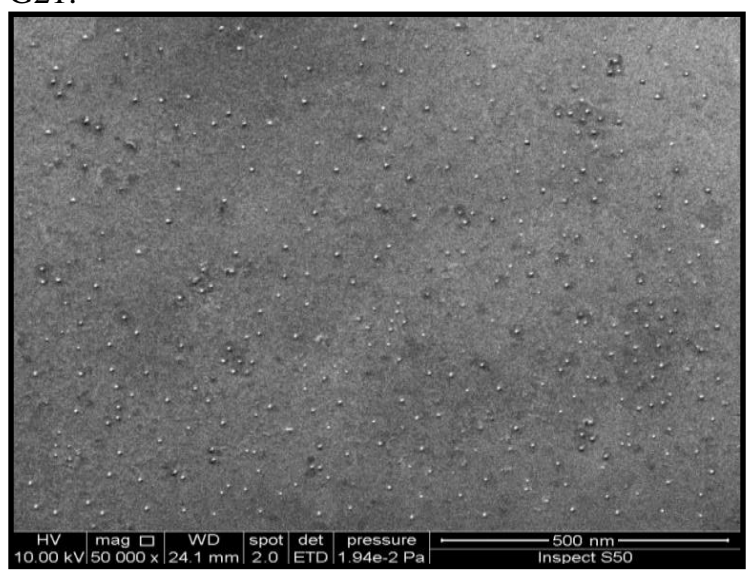

Figure 16. SEM images of the optimized gold nanoparticles G21

\section{Energy dispersive $x$-ray spectroscopy}

EDX measurements considered as good qualitative analysis for different materials due to the number of bremstrahlung x-rays varies with mean atomic number the background counts. Heavy elements as gold (atomic number $\mathrm{Z}=79$ ) quantify easily by comparing the intensity of their peak. Light 
elements; oxygen $(Z=6)$, carbon $(Z=8)$, sodium $(\mathrm{Z}=11)$ and chloride $(\mathrm{Z}=17)$ are difficult to quantify by this method. Hydrogen $(Z=1)$ has too low energy to be detected by EDX and do not have characteristic X-ray peak ${ }^{(39)}$.

EDX analysis (Figure 17) of the optimized suspension G21 gave an optical absorption band peak at approximately $2.2 \mathrm{KeV}$ with high intensity, which was the typical of metallic gold nanocrystallites ${ }^{(16)}$. Elemental mapping analysis showed extreme distribution of metallic gold in the EDX micrograph image (Figure 18).

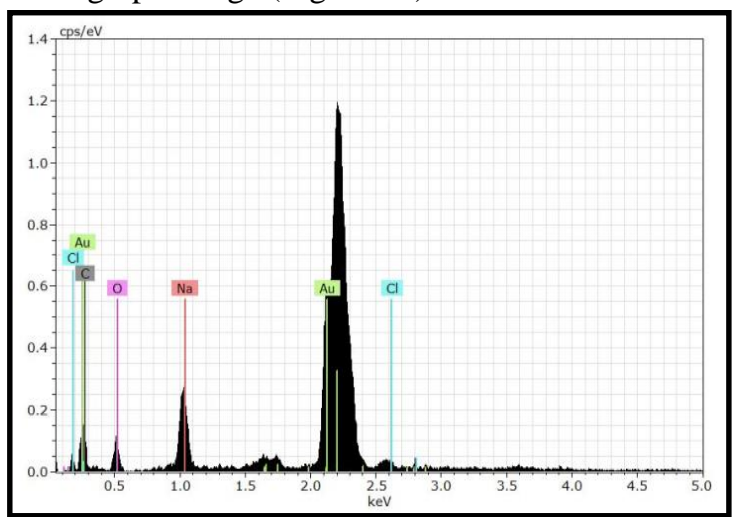

Figure 17. EDX analysis of the optimized gold nanoparticles G21

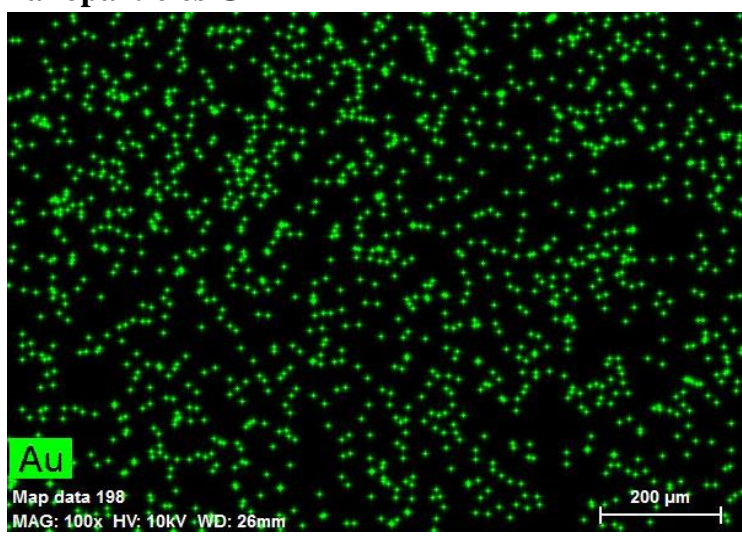

Figure 18. EDX micrograph images for metallic gold distribution of the optimized gold nanoparticles G21

\section{Transmission electron microscopy}

TEM 2D image (Figure 19) of the optimized suspension G21, revealed gold nanoparticles with uniform spherical shape and average particles size $8.81 \mathrm{~nm}$. This data was not significantly $(\mathrm{p}>0.05)$ differed from the data of AFM and SEM analysis (average $8.75 \mathrm{~nm}$ and $8.96 \mathrm{~nm}$ respectively).

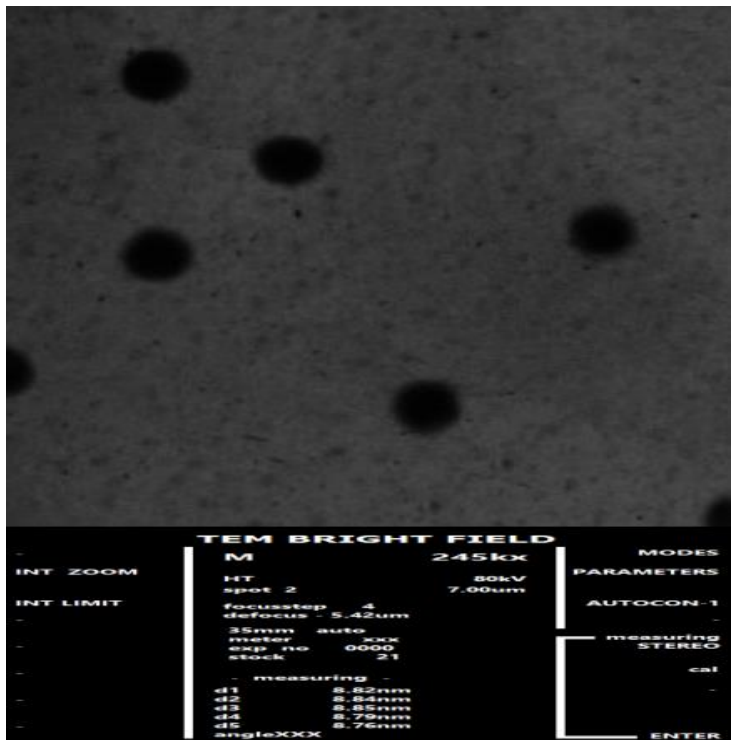

Figure 19. TEM 2D images of the optimized gold nanoparticles G21

\section{Functionalization of gold nanoparticles}

The phenomenon for polymer to enhance the stability of gold nanoparticles depended on the steric repulsion force between polymer moieties, once polymer attached to the outer surface of gold nanoparticles provided enough repulsive potential that can stabilize the dispersion ${ }^{(40,41)}$.

Figures 20 and 21 demonstrated the AFM analysis of the functionalized gold nanoparticles. Increased the particles size of polymeric gold nanoparticles compared to the free gold nanoparticles, with uniform particles size distribution, indicated that gold nanoparticles were indeed conjugated with polymer through coordination bonds ${ }^{(42)}$.

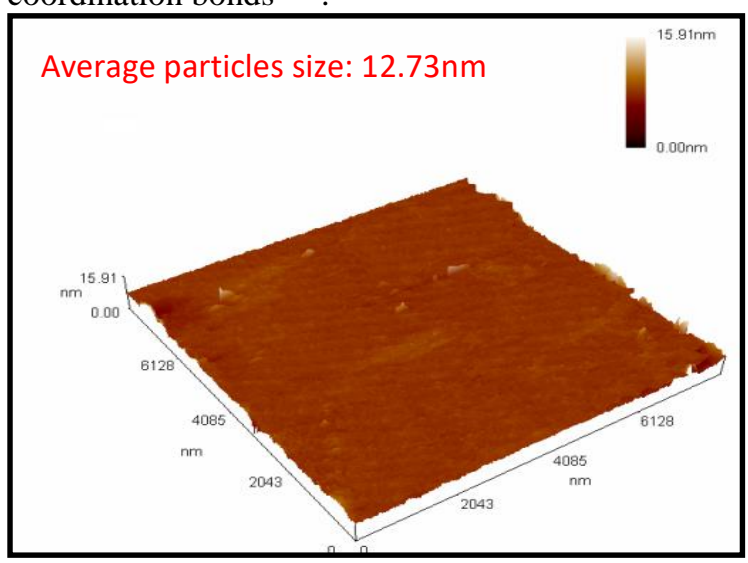

Figure 20. AFM 3D image of polymeric gold nanoparticles 


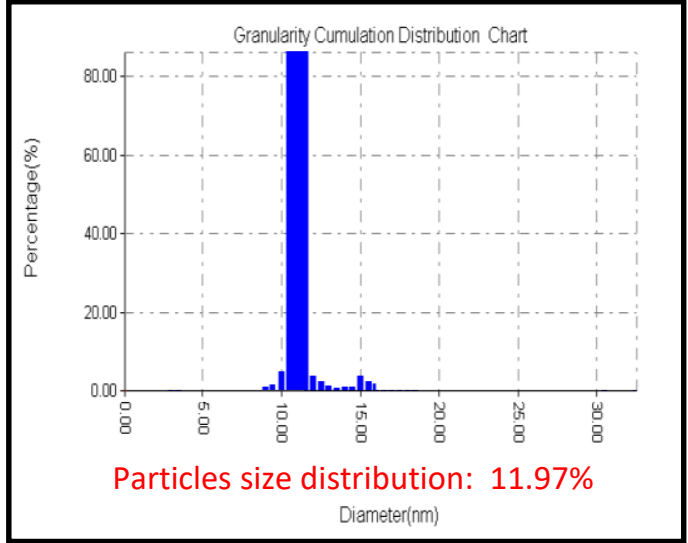

Figure 21.AFM size distribution of polymeric gold nanoparticles

\section{Incorporation of etoposide}

Three formulas of etoposide-loaded gold nanoparticles were prepared by incorporation technique. Polymeric gold nanoparticles with ultra nano-size can give a high surface area for etoposide incorporation. These nanoparticles had a high loading capacity besides the presence of surface active groups (hydroxyl, carboxyl or amide) might the formation of bonds with etoposide per unit area $(43,44)$.

The effect of etoposide loading was evaluated using three different concentrations of etoposide solution $(5,10,15 \mathrm{mg} / \mathrm{ml})$ for formulas $\mathrm{F} 1-\mathrm{F} 3$ respectively. Etoposide solutions of concentration above $5 \mathrm{mg} / \mathrm{ml}$ at $\mathrm{pH} 10.5$ became cloudy within about thirty minutes after preparation, as well as the aqueous etoposide solution became less stable at $\mathrm{pH}$ more than $5^{(45,46)}$, therefore it must be freshly prepared through the incorporation process.

The etoposide loading efficiency was significantly $(\mathrm{p}<0.05)$ decreased with increased the initial loading of etoposide, as shown in Figure 22. F2 and F3 were rejected from experiment.

Figures 23-24 demonstrated the AFM analysis data of formula F1. The etoposide dissolution profile showed a better etoposide retardation at phosphate buffer $\mathrm{pH} 7.4$ and greater release rate with controlled manner at acetate buffer $\mathrm{pH} 4.6$, as shown in Figure $25^{(19,47)}$.

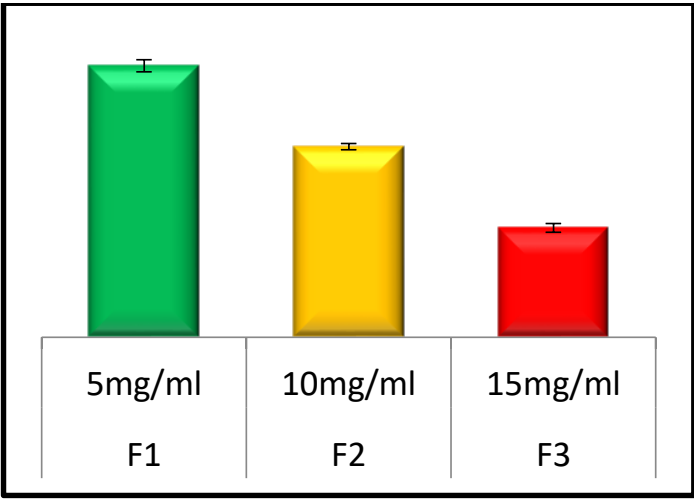

Figure 21. Etoposide loading efficiency of etoposide-loaded gold nanoparticles formula F1 (values are represented as mean $\% \pm \mathrm{SD}$ ).

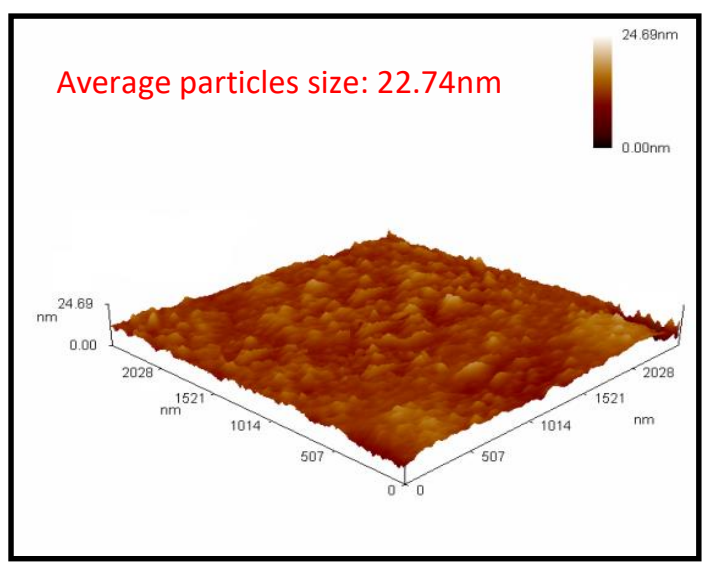

Figure 23. AFM 3D image of etoposide-loaded gold nanoparticles F1.

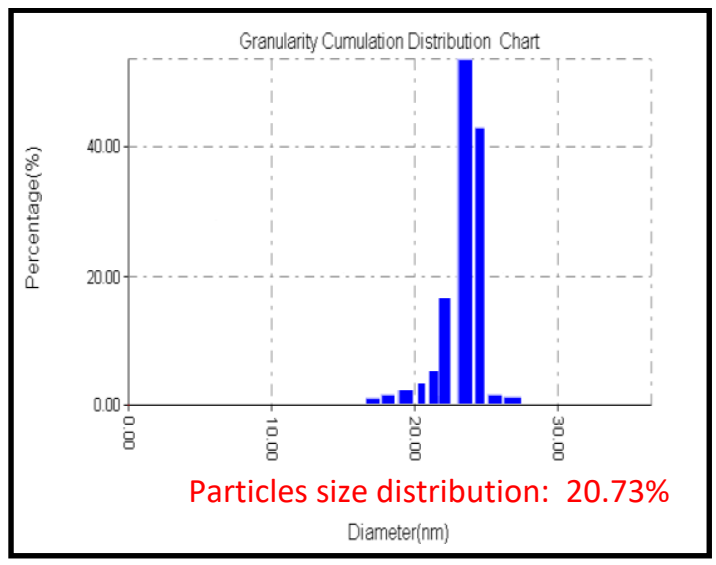

Figure 24. AFM size distribution of etoposideloaded gold nanoparticles F1. 


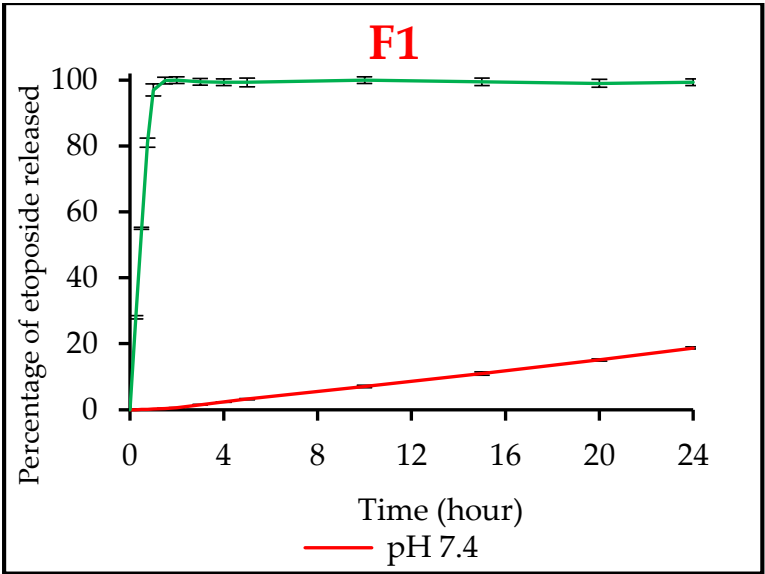

Figure 25. Dissolution profile of etoposide from formula $\mathrm{F1}$ in phosphate (pH 7.4) and acetate (pH 4.6) buffer solutions at $37 \pm 1{ }^{\circ} \mathrm{C}$ (data are represented as mean $\% \pm$ SD for $n=3$ ).

\section{Conclusion}

In conclusion, the citrate reduction method was applied due to its feasibility, scalability and reproducibility. Molar concentration of reactants, preparation temperature and stirring rate had a considerable role in the controlling size and uniformity of gold nanoparticles. As well as, inversed method is seemed to be promising for the preparation of gold nanoparticles with high quality in one step; it can achieve that gold nanoparticles were greatly improved their morphology, size and monodispersity compared to nanoparticles prepared via classical method.

\section{References}

1. Bhatia, Saurabh. Nanoparticles types, classification, characterization, fabrication methods and drug delivery applications. In: Natural polymer drug delivery systems. Springer, Cham, 2016.p33-93.

2. Panzarini, Elisa, et al. Intracellular transport of silver and gold nanoparticles and biological responses: an update. International journal of molecular sciences,2018,19.5:1305.

3. Makhsin, Siti, et al. Synthesis of Gold Nanoparticles and Its Conjugation Strategies to Biomolecules for Biomedical Applications. Reviews in Advanced Sciences and Engineering,2015,4.1:3-21.

4. Herizchi, Roya, et al. Current methods for synthesis of gold nanoparticles. Artificial cells, nanomedicine, and biotechnology,2016,44.2:596-602.

5. Turkevich, John, et al. A study of the nucleation and growth processes in the synthesis of colloidal gold. Discussions of the Faraday Society, 1951,11:55-75.

6. Canbek Ozdil, Z., et al. Competitive Seeded Growth: An Original Tool to Investigate Anisotropic Gold Nanoparticle Growth
Mechanism. The Journal of Physical Chemistry C,2019,123.41:25320-25330.

7. Faridi Majidi, Reza, et al. 'Reversed Turkevich'method for tuning the size of Gold nanoparticles: evaluation the effect of concentration and temperature. Nanomedicine Research Journal,2019,3.4:190-196.

8. Wuithschick, Maria, et al. Turkevich in new robes: key questions answered for the most common gold nanoparticle synthesis. ACS nano,2015,9.7:7052-7071.

9. Andalibi, M., et al. Kinetics and mechanism of gold nanoparticle growth studied via optical extinction spectroscopy and computational modeling. arXiv preprint:1903.06206, 2019.

10. Islam, Zareef, et al. Applications, synthesis and characterization of gold nanoparticles.2017. PhD Thesis. BRAC University.

11. Ţălu, Ştefan, et al. Gold nanoparticles embedded in carbon film: micromorphology analysis. Journal of industrial and engineering chemistry,2016,35:158-166.

12. LAY-Ekuakille, A., et al. Conductivity Image Characterization of Gold Nanoparticles basedDevice through Atomic Force Microscopy. In: 2018 Nanotechnology for Instrumentation and Measurement (NANOfIM). IEEE,2018.p1-6.

13. Kettemann, Frieder, et al. Missing piece of the mechanism of the Turkevich method: the critical role of citrate protonation. Chemistry of Materials,2016,28.11:4072-4081.

14. EL-Naggar, Mehrez, et al. Eco-friendly microwave-assisted green and rapid synthesis of well-stabilized gold and core-shell silvergold nanoparticles. Carbohydrate polymers,2016,136:1128-1136.

15. Vasantharaj, S., et al. Surface active gold nanoparticles biosynthesis by new approach for bionanocatalytic activity. Journal of Photochemistry and Photobiology B:Biology,2018,179:119-125.

16. Vladár, András, et al. Characterization of nanoparticles by scanning electron microscopy. In: Characterization of Nanoparticles. Elsevier,2020.p7-27.

17. Tahir, Kamran, et al. Nerium oleander leaves extract mediated synthesis of gold nanoparticles and its antioxidant activity. Materials Letters,2015,156:198-201.

18. Michen, Benjamin, et al. Avoiding dryingartifacts in transmission electron microscopy: Characterizing the size and colloidal state of nanoparticles. Scientific reports,2015,5:9793.

19. Suarasan, S.; Focsan, M.; Potara, M.; Soritau, O.; Florea, A.; Maniu, D.; Astilean, S. Doxorubicin-incorporated nanotherapeutic delivery system based on gelatin-coated gold nanoparticles: formulation, drug release, and multimodal imaging of cellular 
internalization. ACS Appl Mater Interfaces 2016, 8, 22900-22913.

20. Khodashenas, B.; Ardjmand, M.; Baei, M.S.; Rad, A.S.; Khiyavi, A.A. Gelatin-gold nanoparticles as an ideal candidate for curcumin drug delivery: Experimental and DFT Studies. JIOPM 2019, 29, 2186-2196.

21. Farooq, M.U.; Novosad, V.; Rozhkova, E.A.; Wali, H.; Ali, A.; Fateh, A.A.; Neogi, P.B.; Neogi, A.; Wang, Z. Gold nanoparticlesenabled efficient dual delivery of anticancer therapeutics to HeLa cells. Scientific Reports 2018, 8, 2907, 1-12.

22. Haddada, M. B.; Jeannot, K.; Spadavecchia, J. Novel Synthesis and Characterization of Doxycycline-Loaded Gold Nanoparticles: The Golden Doxycycline for Antibacterial Applications. PPSC 2019, 36, 1800395, 1-11

23. Manivasagan, P.; Bharathiraja, S.; Bui, N.Q.; Jang, B.; Oh, Y.O.; Lim, I.G.; Oh, J. Doxorubicin-loaded fucoidan capped gold nanoparticles for drug delivery and photoacoustic imaging. Int J Biol Macromol 2016, 91, 578-588.

24. Amanlou, N.; Parsa, M.; Rostamizadeh, K.; Sadighian, S.; Moghaddam, F. Enhanced cytotoxic activity of curcumin on cancer cell lines by incorporating into gold/chitosan nanogels. Mater Chem Phys 2019, 226, 151157

25. Karimi, S., et al. Controlled synthesis of colloidal monodisperse gold nanoparticles in a wide range of sizes; investigating the effect of reducing agent. Materials Research Express,2019,6.11:1150f2.

26. Piella, j., et al. Size-controlled synthesis of sub10-nanometer citrate-stabilized gold nanoparticles and related optical properties. Chemistry of Materials,2016,28.4:1066-1075.

27. Zabetakis, Kara, et al. Effect of high gold salt concentrations on the size and polydispersity of gold nanoparticles prepared by an extended Turkevich-Frens method. Gold Bulletin,2012,45.4:203-211.

28. Agunloye, Emmanuel, et al. A model for the formation of gold nanoparticles in the citrate synthesis method. Chemical Engineering Science, 2018,191:318-331.

29. He, Qijin, et al. Study of color change in seedmediated growth of gold nanoparticles and insights into Turkevich method. 2019.

30. Suchomel, Petr, et al. Simple size-controlled synthesis of $\mathrm{Au}$ nanoparticles and their sizedependent catalytic activity. Scientific reports, 2018,8.1:4589.

31. Shi, Li, et al. How does the size of gold nanoparticles depend on citrate to gold ratio in Turkevich synthesis? Final answer to a debated question. Journal of colloid and Interface Science,2017,492:191-198.
32. LI, Chunfang, et al. Facile synthesis of concentrated gold nanoparticles with low sizedistribution in water: temperature and $\mathrm{pH}$ controls. Nanoscale research letters, 2011,6.1:440.

33. Tran, Minh, et al. Effect of citrate ratio and temperature on gold nanoparticle size and morphology. Materials

Research Express,2016,3.10:105027.

34. Georgiev, Peter, et al. Implementing atomic force microscopy (AFM) for studying kinetics of gold nanoparticle's growth. Colloids and Surfaces A: Physicochemical and Engineering Aspects, 2013,434:154-163.

35. Abécassis, Benjamin, et al. Influence of monomer feeding on a fast gold nanoparticles synthesis: time-resolved XANES and SAXS experiments. Langmuir,2010,26.17:1384713854.

36. Verma, Harihar, et al. Gold nanoparticle: synthesis and characterization. Veterinary world, 2014,7.2:72.

37. Haider, Adawiya, et al. Synthesis and stabilization of gold nanoparticles by inverse reduction method using sodium citrate and sodium boro hydride as reducing agent. Journal of university of Anbar for Pure science,2016,10.1:37-47.

38. Rajeshwari, A., et al. Interaction of citratecapped gold nanoparticles with the selected amino thiols for sensing applications. Proceedings of the National Academy of Sciences, India Section B:Biological Sciences, 2017,87.1:23-30.

39. Slater, Thomas, et al. STEM-EDX tomography of bimetallic nanoparticles: A methodological investigation. Ultramicroscopy,2016,162:6173.

40. Napper, D.H. Steric stabilization. J Colloid Interf Sci 1977, 58, 390-407.

41. Madkour, M.; Bumajdad, A.; Al-Sagheer, F. To what extent do polymeric stabilizers affect nanoparticles characteristics?. Adv Colloid Interface Sci 2019, 270, 38-53. Lay-Ekuakille, A.; Spano, F.; Mvemba, P.K.; Massaro, A.; Galiano, A.; Casciaro, S.; Conversano, F. Conductivity image characterization of gold nanoparticles based-device through atomic force microscopy. NANOfIM, 2018, 1-6.

42. Suarasan, S.; Simon, T.; Boca, S.; Tomuleasa, C.; Astilean, S. Gelatin-coated Gold Nanoparticles as Carriers of FLT 3 Inhibitors for Acute Myeloid Leukemia Treatment. Chem Biol Drug Des 2016, 87, 927-935.

43. Kong, F.Y.; Zhang, J.W.; Li, R.F.; Wang, Z.X.; Wang, W.J.; Wang, W. Unique roles of gold nanoparticles in drug delivery, targeting and imaging applications. Molecules 2017, 22, 1445, 1-13. 
44. Brayfield, A. Martindale: The Complete Drug Reference. 39 ${ }^{\text {th }}$ Edition. Pharmaceutical Press 2017.

45. Wojtkowiak, J.W.; Verduzco, D.; Schramm, K.J.; Gillies, R.J. Drug resistance and cellular adaptation to tumor acidic $\mathrm{pH}$ microenvironment. Molecular pharmaceutics 2011, 8(6): 2032-2038.
46. Amanlou, N.; Parsa, M.; Rostamizadeh, K.; Sadighian, S.; Moghaddam, F. Enhanced cytotoxic activity of curcumin on cancer cell lines by incorporating into gold/chitosan nanogels. Materials Chemistry and Physics 2019, 226: 151-157.

Baghdad Iraqi Journal Pharmaceutical Sciences by bijps is licensed under a Creative Commons Attribution 4.0 International License. Copyrights@ 2015 College of Pharmacy - University of Baghdad. 